\title{
A novel bispidinone analog induces S-phase cell cycle arrest and apoptosis in HeLa human cervical carcinoma cells
}

\author{
XU YI ${ }^{1-3}$, XIN ZHANG ${ }^{1,2}$, HYUNJIN JEONG $^{1}$, YU MI SHIN ${ }^{1}$, DONG HO PARK ${ }^{1}$, \\ SONG YOU ${ }^{2}$ and DONG-KYOO KIM ${ }^{1}$
}

\author{
${ }^{1}$ Department of Chemistry and Institute of Basic Sciences, Inje University, Gimhae 621-749, Republic of Korea; \\ ${ }^{2}$ School of Life Science and Biopharmaceutics, Shenyang Pharmaceutical University, Shenyang, Liaoning 110016; \\ ${ }^{3}$ Department of Pharmacy, The First People's Hospital of Lianyungang, Lianyungang, Jiangsu 222002, P.R. China
}

Received October 9, 2014; Accepted December 3, 2014

DOI: $10.3892 /$ or.2015.3722

\begin{abstract}
Tetranitrophenyl-3,7-diazabicyclo[3.3.1] nonan-9-one (B16), a bispidinone analog, was synthesized to investigate its effects on cell viability, the cell cycle, and apoptotic pathways in HeLa human cervical cancer cells. B16 decreased the percentage of viable cells in WST-8 assays, and morphological changes associated with apoptotic cell death were observed, including cell shrinkage and disruption. Annexin V-FITC/PI dual staining assays showed that B16 significantly increased the early apoptosis of HeLa cells after $24 \mathrm{~h}$ of treatment. Moreover, DNA content analysis and $\left[{ }^{3} \mathrm{H}\right]$-thymidine incorporation assays showed that B16 induced S-phase cell cycle arrest and inhibited DNA replication after $24 \mathrm{~h}$ of treatment. Following treatment with $25 \mu \mathrm{M}$ of B16, an increase in reactive oxygen species and a decrease in mitochondrial membrane potential were observed by flow cytometry. In addition, the expression levels of caspase cascade and $\mathrm{Bcl}-2$ family proteins determined by western blotting suggested that the induction of apoptosis by B16 was associated with a caspase- and mitochondrial-dependent pathway in HeLa cells. In conclusion, B16 induced early apoptosis and S-phase cell cycle arrest in HeLa cells via a caspase- and mitochondrial-dependent pathway.
\end{abstract}

\section{Introduction}

Cervical carcinoma is the second most common type of cancer in women and is the most prevalent female malignancy

Correspondence to: Professor Dong-Kyoo Kim, Department of Biomedicinal Chemistry and Institute of Basic Science, Inje University, 607 Aubang-Dong, Gimhae 621-749, Republic of Korea E-mail: chemkdg@inje.ac.kr

Professor Song You, School of Life Science and Biopharmaceutics, Shenyang Pharmaceutical University, 103 Wenhua Road, Shenyang, Liaoning 110016, P.R. China

E-mail: yousong206@aliyun.com

Key words: bispidinone analog, cell cycle arrest, apoptosis, HeLa cells, mitochondria, caspases in many developing countries $(1,2)$. Although the efficacy of chemotherapy for the majority of cancer types has improved over the last three decades, the severe reduction in quality of life caused by highly toxic effects of chemotherapeutic drugs is still a formidable problem in clinical medicine $(3,4)$. Therefore, the development and mechanistic investigation of chemotherapeutic or chemopreventive agents against cervical carcinoma are important steps towards reducing the incidence and mortality of this disease (5). Apoptotic and cell cycle control have recently attracted the attention of investigators for the development of novel anticancer agents $(6,7)$.

Apoptosis is a highly regulated cellular process that maintains the physiological balance of an organism by eliminating unwanted and defective cells through an orderly process of cell disintegration (8). Apoptosis is characterized by morphological changes such as membrane blebbing, cytoplasmic and chromatin condensation, and apoptotic body formation (9). Biochemical changes including cysteine-dependent aspartatedirected protease (caspase) activation, DNA fragmentation, and phosphatidylserine translocation are also associated with apoptosis (10). The death receptor and mitochondrial pathway are known to lead to apoptosis. The death receptor pathway is triggered by members of the death receptor super family. The formation of a death-inducing signaling complex, clustered by $\mathrm{CD} 95$, leads to the recruitment of multiple procaspase- 8 molecules via the adapter molecule FADD (Fas-associated death domain protein), resulting in caspase- 8 activation. The mitochondrial pathway, which is regulated primarily by the Bcl-2 family, may be caused by the opening of the mitochondrial permeability transition pore, resulting in a decline of mitochondrial membrane potential (MMP), failure of $\mathrm{Ca}^{2+}$ control (11), generation of reactive oxygen species (ROS) (12), and the release of pro-apoptotic proteins (13). In the early stage of apoptosis, the pro-apoptotic protein Bax translocates from the cytosol to the mitochondria, leading to an efflux of cytochrome $c$ (14), which then binds to Apaf-1 and forms the apoptosome. The apoptosome recruits and activates procaspase- 9 , which in turn activates downstream executioner caspases, such as caspase- $3,-6$, and $-7(15,16)$.

The cell cycle is defined as a set of events responsible for cell duplication (17). The progression of cell cycle events is monitored at checkpoints that occur at the G1/S boundary, 
during the $\mathrm{S}$ phase, and during the $\mathrm{G} 2 / \mathrm{M}$ phase (18). In a normal cell cycle, the $\mathrm{M}$ phase always follows the $\mathrm{S}$ phase and does not occur until the $\mathrm{S}$ phase is complete. The cell cycle checkpoints are activated by DNA damage and by the misalignment of chromosomes at the mitotic spindle (19). In this case, the growth arrest caused by checkpoint mechanisms allows the cell to repair the damage, after which progression through the cell cycle resumes. If the damage cannot be repaired, the cell is eliminated through apoptosis $(20,21)$.

3,7-Diazabicyclo[3.3.1]nonane, known as bispidinone, is of biological interest owing to its presence in the molecular structure of various alkaloids, such as diterpene, norditerpene, and lupin (22). The antibacterial and antifungal efficiency of bispidinone analogs have led to their use as templates for the improvement of antimicrobial agents (23). Furthermore, it has been confirmed that bispidinone analogs exert anticancer effects in HeLa cells via mitochondrial-mediated apoptosis. In this study, we determined the anticancer effects of a novel bispidinone analog, 2,4,6,8-(3)-tetranitrophenyl-3,7-diazabicyclo[3.3.1]nonan-9-one (B16) (Fig. 1), and investigated the underlying molecular mechanism of its activities.

\section{Materials and methods}

Chemicals. Bispidinone and bispidinone analogs were obtained from the laboratory of Dr D.H. Park. Stock solution of the samples was dissolved in dimethyl sulfoxide (DMSO) as $20 \mathrm{mM}$ and kept at $4^{\circ} \mathrm{C}$. Further dilutions were made immediately prior to each experiment. Eagle's minimal essential medium (EMEM), penicillin-streptomycin and trypsin-EDTA were purchased from HyClone (Logan, UT, USA). Fetal bovine serum (FBS) was obtained from Gibco-BRL (Carlsbad, CA, USA). The Cell Counting Kit-8 (CCK-8) was obtained from Dojindo (Osaka, Japan). The propidium iodide (PI)/RNase staining buffer and Annexin-FITC kit for apoptosis were from BD Pharmingen (San Diego, CA, USA).

Cell culture. HeLa cells were obtained from the American Type Culture Collection (ATCC; Manassas, VA, USA) and were cultured in EMEM supplemented with $10 \%$ FBS and 1\% penicillin-streptomycin at $37^{\circ} \mathrm{C}$ in a humidified atmosphere with $5 \% \mathrm{CO}_{2}$.

Cell viability and proliferation assay. HeLa cells were plated at $5 \times 10^{3}$ cells/well in a 96-well microplate. After $24 \mathrm{~h}$, the media were substituted with fresh media containing B16 at concentrations of 7.5, 15 and $30 \mu \mathrm{M}$. The plate was incubated for $48 \mathrm{~h}$ and cell viability was assessed using a WST-8 assay according to the manufacturer's recommendations (24). CCK-8 solution $(10 \mu \mathrm{l})$ was added to each well of the plate followed by 2 -h incubation. The optical density for viable cells was read at $450 \mathrm{~nm}$ in a multimicroplate reader (Synergy HT; BioTek Instruments, Inc. Winooski, VT, USA). For the effect of B16 on HeLa cell proliferation, the cells were seeded at $5 \times 10^{3}$ cells $/ \mathrm{ml}$ media in 96 -well plates and treated with or without B16 $(25 \mu \mathrm{M})$ at various time points. Each experiment was repeated at least three times.

Measurement of apoptotic cell morphology. HeLa cells were distributed $\left(2 \times 10^{5}\right.$ cells/well) into a 6 -well plate and allowed to

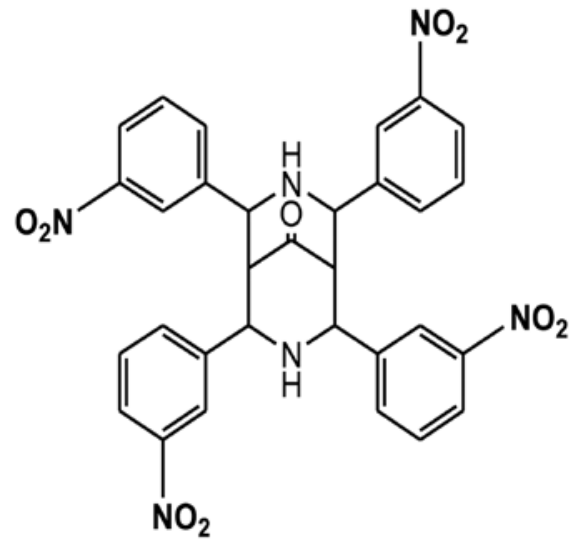

Figure 1. Chemical structure of B16.

adhere overnight. The cells were treated with B16 $(25 \mu \mathrm{M})$ for 24 and $48 \mathrm{~h}$. Non-treated wells received an equivalent volume of DMSO $(<0.1 \%)$ as a control. Optic phase-contrast images were captured with a Phase Contrast-2, ELWD 0.3 inverted microscope (Nikon, Japan).

Annexin V-FITC/PI apoptotic analysis. Cells $\left(3 \times 10^{5}\right)$ in a 60-mm Petri dish, treated with or without B16, were collected by trypsinization and washed with ice-cold phosphate buffered saline (PBS) via centrifugation at 2,500 $\mathrm{g}$ for $3 \mathrm{~min}$. Cells $\left(1 \times 10^{5}\right)$ were resuspended in $100 \mu \mathrm{l}$ of binding buffer and stained with $5 \mu \mathrm{l}$ of Annexin V-FITC and $10 \mu \mathrm{l}$ of PI $(50 \mu \mathrm{g} / \mathrm{ml})$ for $15 \mathrm{~min}$ at room temperature, in the dark. Analysis was performed by FACSCalibur flow cytometer (Becton-Dickinson, San Jose, CA, USA) with 10,000 events/analysis. The data were analyzed using Cell Quest Pro software (Becton-Dickinson Instruments, Franklin Lakes, NJ, USA).

Cell cycle arrest assay. Cells $\left(3 \times 10^{5}\right)$ in a $60-\mathrm{mm}$ Petri dish, treated with or without B16, were collected by trypsinization and washed with ice-cold PBS via centrifugation as above. The cells were suspended in PBS and fixed with 70\% ethanol (v/v). Samples were washed with ice-cold PBS and stained with PI/RNase staining buffer for $15 \mathrm{~min}$ at room temperature. The number of cells in different phases of the cell cycle was analyzed using a FACScan flow cytometer analysis system and 20,000 events were analyzed each time. The percentage of cells in different phases of the cell cycle was determined using Modifit software (Becton-Dickinson Instruments).

$\left[{ }^{3} \mathrm{H}\right]$-thymidine incorporation assay. Briefly, the HeLa cells were applied to 12 -well plates in growth medium (EMEM $+10 \% \mathrm{FBS}+1 \%$ penicillin-streptomycin). After the cells had grown to $70-80 \%$ confluence, they were rendered quiescent by incubation for $24 \mathrm{~h}$ in EMEM containing $2 \% \mathrm{FBS}$. The cells were treated with or without B16 in EMEM supplemented with $10 \%$ FBS and the cultures were incubated for 21 or $45 \mathrm{~h} .\left[{ }^{3} \mathrm{H}\right]-\mathrm{dTTP}$ was added at $1 \mu \mathrm{Ci} / \mathrm{ml}(1 \mu \mathrm{Ci}=37 \mathrm{kBq})$ and incubated for an additional $3 \mathrm{~h}$. Incorporated $\left[{ }^{3} \mathrm{H}\right]$-dTTP was extracted in cell lysis buffer and measured in a liquid scintillation analyzer (Tris-Crab 2910TR; Perkin-Elmer Inc., Waltham, MA, USA) (25). 

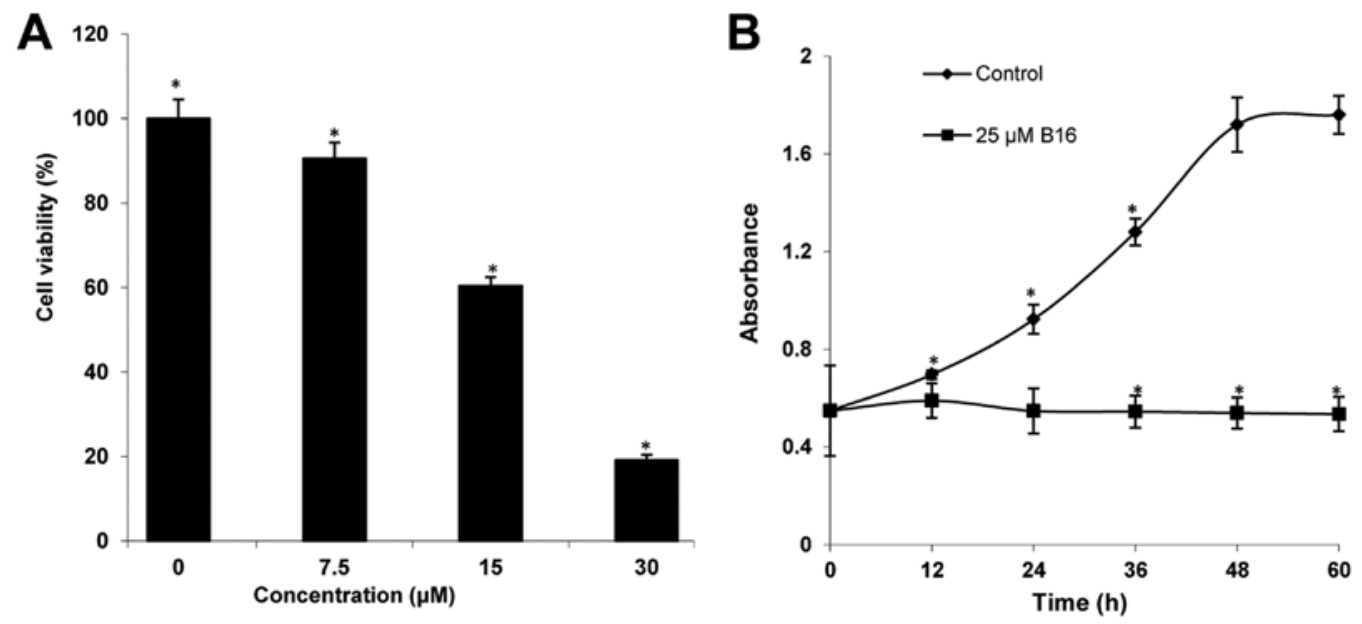

Figure 2. Effects of B16 on HeLa cell cytotoxicity and proliferation. (A) HeLa cells were treated with different concentrations (0-30 $\mu \mathrm{M})$ of B16 for $48 \mathrm{~h}$. (B) HeLa cells were treated with $25 \mu \mathrm{M}$ of B16 for varying lengths of time $(0-60 \mathrm{~h})$, and the cell viability was measured using a Cell Counting Kit-8. Results are the mean $\pm \mathrm{SD}, \mathrm{n}=3 .{ }^{*} \mathrm{P}<0.05$, significantly different from the control at the same level.

Measurement of intracellular ROS. Generation of ROS was assessed using the fluorescent indicator 2,7-dichlorodihydrofluorescein $\left(\mathrm{H}_{2} \mathrm{DCF}-\mathrm{DA}\right)$, a cell-permeable indicator for ROS shown to react with $\mathrm{H}_{2} \mathrm{O}_{2}$ (26). As previously described, $\mathrm{H}_{2}$ DCF-DA was oxidized to highly green fluorescent 2,7-dichlorofluorescein (DCF) by the generation of ROS. Cells $\left(3 \times 10^{5}\right)$ in a $60-\mathrm{mm}$ dish, treated with or without B16, were collected by trypsinization and centrifugation as describe above. The samples were washed with ice-cold PBS and

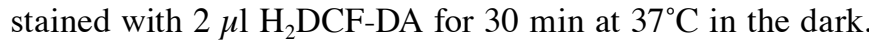
Relative fluorescence intensities were monitored using the FACSCalibur flow cytometer and analyzed using CellQuest software with the FL-1 channel (green) set to $530 \mathrm{~nm}$.

Measurement of mitochondrial-membrane potential. Rhodamine 123 was used as a fluorescent probe to detect the depolarization of mitochondrial-membrane potential. During apoptosis, the integrity of the mitochondrial membrane is disrupted, leading to depolarization of the membrane, opening of mitochondrial permeability transition pores and release of sequestered rhodamine 123 . Cells $\left(3 \times 10^{5}\right)$ in a $60-\mathrm{mm}$ Petri dish), treated with or without B16, were collected by trypsinization and centrifugation as described above. The samples were washed with ice-cold PBS and stained with $5 \mu \mathrm{l}$ rhodamine 123 for $30 \mathrm{~min}$ at $37^{\circ} \mathrm{C}$ in the dark. Relative fluorescence intensities were monitored using a FACSCalibur flow cytometer and analyzed using Cell Quest software with the FL-1 channel.

Western blot analysis. Following treatment of cells with or without B16, total cell lysates was prepared as previously described. Protein contents of the lysates were determined by the Bradford protein assay (Bio-Rad, Hercules, CA, USA). Proteins $(8 \mu \mathrm{g})$ were resolved by sodium dodecyl sulfate polyacrylamide gel electrophoresis (SDS-PAGE) and transferred onto nitrocellulose membranes (Schleicher \& Schuell, BioScience, Inc., Keene, NH, USA) by western blotting. The results were quantified using Image J v. 1.43 software (National Institutes of Health, Bethesda, MD, USA). The following primary polyclonal antibodies were used: $\beta$-actin, Bcl-2, procaspase-9, procaspase-8 (1:1,000 dilution; Cell Signaling Technology Inc., Danvers, MA, USA), procaspase-3, p53 (1:300; Santa Cruz Biotechnology, Inc., Santa Cruz, CA, USA) and Bax (1:1,000; BD Pharmingen, San Diego, CA, USA).

Statistical analysis. Results reported were obtained from at least three independent experiments with similar results. The results are presented as mean \pm standard deviation (SD) in quantitative experiments. Statistical analysis was performed by one-way analysis of variance (ANOVA). ${ }^{*} \mathrm{P}<0.05$ was considered to indicate a statistically significant difference. Microsoft Excel 2007 was used for statistical and graphical evaluations.

\section{Results}

Cytotoxic effect of B16 in HeLa cells. The cytotoxicity of B16 was determined using WST- 8 assays. After incubation with increasing concentrations $(7.5,15$, and $30 \mu \mathrm{M})$ for $48 \mathrm{~h}, \mathrm{~B} 16$ showed significant cytotoxicity in HeLa cells in a concentration-dependent manner, compared to the control (Fig. 2A). The $\mathrm{IC}_{50}$ value of B16 was $22.66 \mu \mathrm{M}$. In addition, the proliferation of HeLa cells treated with $25 \mu \mathrm{M}$ of B16 was measured at 12-h intervals for $60 \mathrm{~h}$. As shown in Fig. 2B, the proliferation of HeLa cells treated with B16 continuously increased during the first $12 \mathrm{~h}$, and then the proliferation rate observed at $12 \mathrm{~h}$ was maintained until $60 \mathrm{~h}$. By contrast, the control cells maintained an exponential proliferation state throughout the 60-h incubation. These results suggested that B16 reduced the viability of HeLa cells in a dose- and time-dependent manner.

Morphological changes and early apoptosis induced by B16 in HeLa cells. Morphological observation using light microscopy was performed to study B16-induced apoptosis in HeLa cells. As shown in Fig. 3A, the untreated cells spread regularly in culture plates and grew to near confluence. After $24 \mathrm{~h}$ of treatment with B16, some of the cells floated in the culture plates, while the majority of the attached cells maintained a shrunken shape. After $48 \mathrm{~h}$ of treatment, a significant proportion of the HeLa cells dislodged from the plates and the remaining adherent cells showed typical morphological 
A

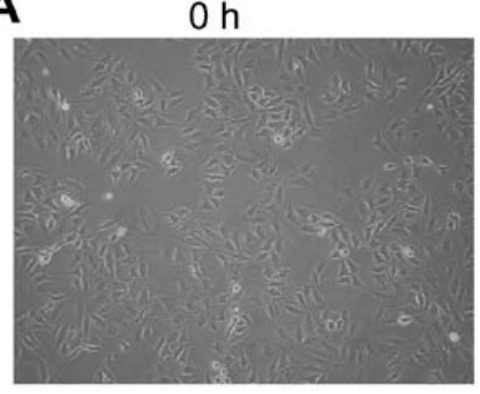

B

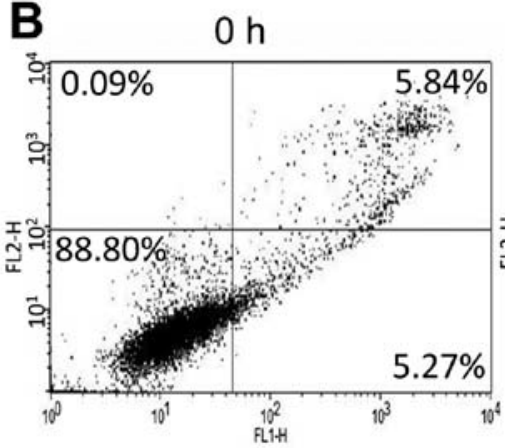

$24 \mathrm{~h}$

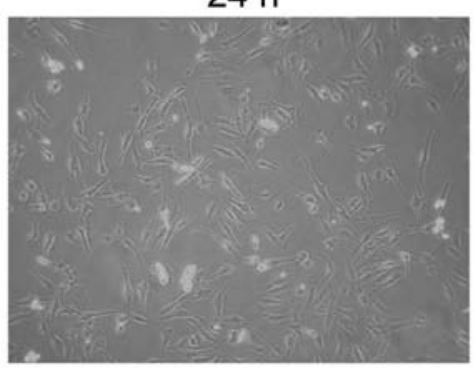

$24 \mathrm{~h}$

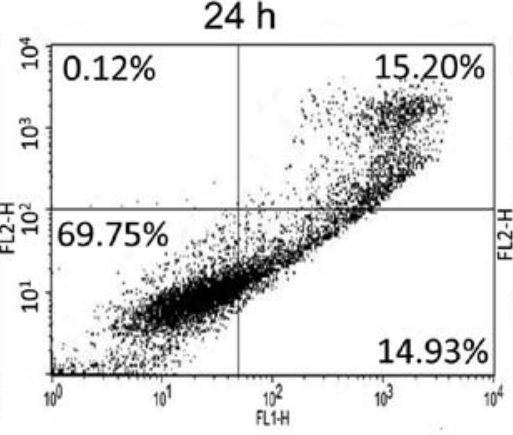

$48 \mathrm{~h}$

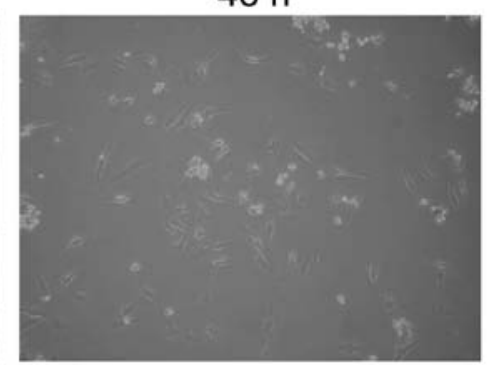

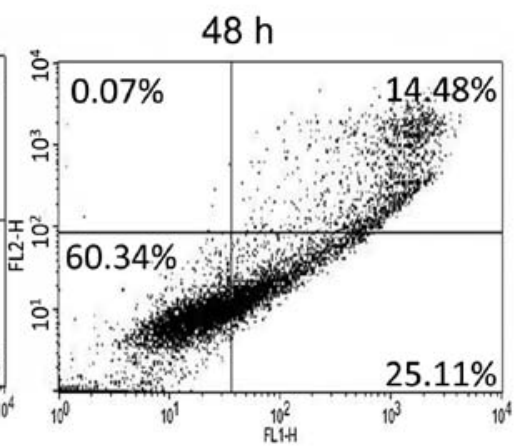

Figure 3. Induction of morphological changes and early apoptosis by B16. Exponentially growing HeLa cells were treated with B16 for varying lengths of time (0-48 h). (A) Morphological changes in HeLa cells under light microscopy. Magnification, x160. (B) Cells were harvested, stained with Annexin V-FITC/PI and analyzed for apoptosis by flow cytometry. Experiments were performed in triplicate and yielded similar results. Results are the mean \pm SD, $\mathrm{n}=3$. ${ }^{*} \mathrm{P}<0.05$, significantly different from the control at the same level.

changes, such as shrinkage, floating, and an increase in intercellular space. To assess the induction of apoptosis by B16 in HeLa cells, an Annexin V and PI double staining assay was performed. A 48-h treatment with B16 significantly increased the percentage of cells undergoing early apoptosis from $5.27(0 \mathrm{~h})$ to $25.11 \%(48 \mathrm{~h})$ (Fig. 3B). In addition, the percentage of cells in late apoptosis (necrotic cells) was also increased by B16 treatment (Fig. 3B).

Induction of cell cycle arrest by B16. Cell growth and inhibition are tightly mediated through cell cycle control mechanisms (27). To examine the effects of B16 on the cell cycle, a DNA content assay was performed to analyze the cell cycle distribution of HeLa cells treated with $25 \mu \mathrm{M}$ B16. In the cells undergoing apoptosis, a DNA peak that is characteristic of apoptosis (usually known as the sub-G0/G1 peak or apoptotic peak) appeared (Fig. 4). After $24 \mathrm{~h}$ of treatment, B16 induced a significant accumulation of cells in the $\mathrm{S}$ phase (21.44\% in control cells vs. $29.21 \%$ in the B16-treated cells). Concomitantly, there was a significant decrease of cells in the G1 phase from 64.95 in the control cells to $48.88 \%$ in the B16-treated cells. The level of S-phase arrest induced by B16 in HeLa cells did not appear to be time dependent.

Inhibition of $\left[{ }^{3} \mathrm{H}\right]$-thymidine incorporation by $\mathrm{Bl}$ in $\mathrm{HeLa}$ cells. The results of the DNA content assay suggested that HeLa cells treated with B16 accumulated in the S phase. To confirm this hypothesis, we analyzed DNA replication in HeLa cells treated with B16 by determining the incorporation of $\left[{ }^{3} \mathrm{H}\right]$-dTTP. In cells treated with B16 for $24 \mathrm{~h}$ and $48 \mathrm{~h},\left[{ }^{3} \mathrm{H}\right]$-dTTP incorporation was reduced by 30 and $60 \%$, respectively, compared to the controls (Fig. 5). This result suggested that B16 had an inhibitory effect on the process of DNA replication.

Effect of B16 on ROS generation and MMP levels in HeLa cells. ROS plays an increasingly important role in apoptosisinduced cell death (28). Therefore, we determined the effect of B16 on ROS generation by measuring the fluorescence of the cell-permeable dye $\mathrm{H}_{2} \mathrm{DCF}-\mathrm{DA}$ in HeLa cells during a 6-h treatment with $25 \mu \mathrm{M}$ B16. The mean $\mathrm{H}_{2} \mathrm{DCF}-\mathrm{DA}$ fluorescence value increased from $49.78(0 \mathrm{~h})$ to $101.98(3 \mathrm{~h})$ following treatment with $\mathrm{B} 16$, whereas the value of $\mathrm{H}_{2} \mathrm{DCF}-\mathrm{DA}$ fluorescence decreased after the 3-h time point (Fig. 6A). These results indicate that treatment with B16 induced changes in ROS generation.

The generation of ROS is associated with the disruption of the mitochondrial-membrane potential, and mitochondrial-membrane depolarization is considered to be a crucial hallmark of apoptosis. In our study, rhodamine 123 was used as a fluorescent probe to detect the loss of MMP. Fig. 6B shows that the mean rhodamine 123 fluorescence decreased from $86.97(0 \mathrm{~h})$ to $82.8(12 \mathrm{~h})$ and $74.83(24 \mathrm{~h})$ following treatment with $25 \mu \mathrm{M}$ B16, suggesting that mitochondria were involved in the observed B16-induced apoptosis.

Involvement of protein activation in B16-induced apoptosis. To investigate the underlying mechanism of apoptosis induced by B16, the expression levels of several apoptosis-associated proteins were determined by western blot analysis. As shown in Fig. 7A, a decrease in procaspase-3 and -9 expression levels was observed in cells treated with B16, demonstrating the activation of the caspase cascade in these cells. We also assessed the expression level of p53, a known tumor suppressor, and found 

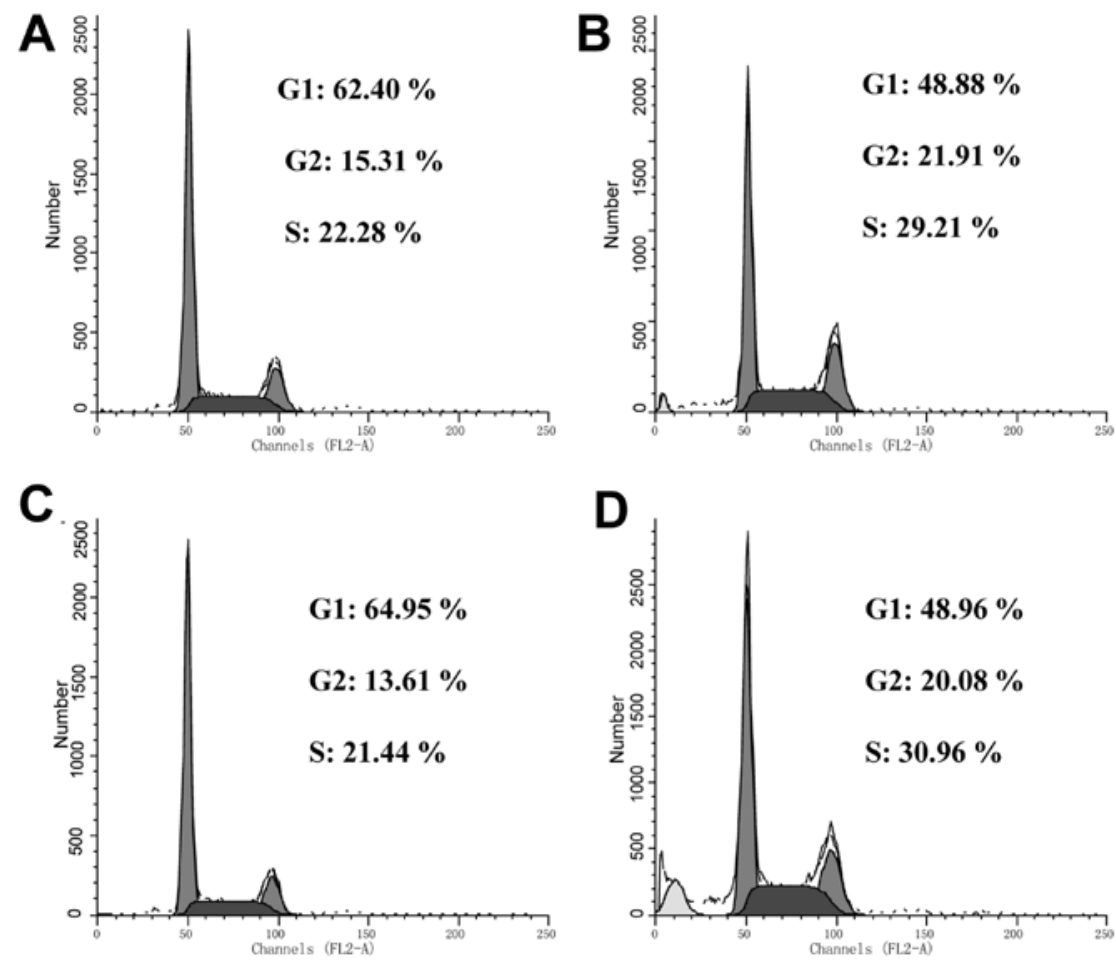

Figure 4. Effects of B16 on cell cycle distribution. HeLa cells were not treated at (A) $24 \mathrm{~h}$, (C) $48 \mathrm{~h}$. HeLa cells were treated with $25 \mu \mathrm{M}$ of B16 for (B) $24 \mathrm{~h}$ and (D) $48 \mathrm{~h}$, and cell cycle distribution was monitored by flow cytometry. Results are the mean $\pm \mathrm{SD}, \mathrm{n}=3$. ${ }^{*} \mathrm{P}<0.05$, significantly different from the control at the same level.

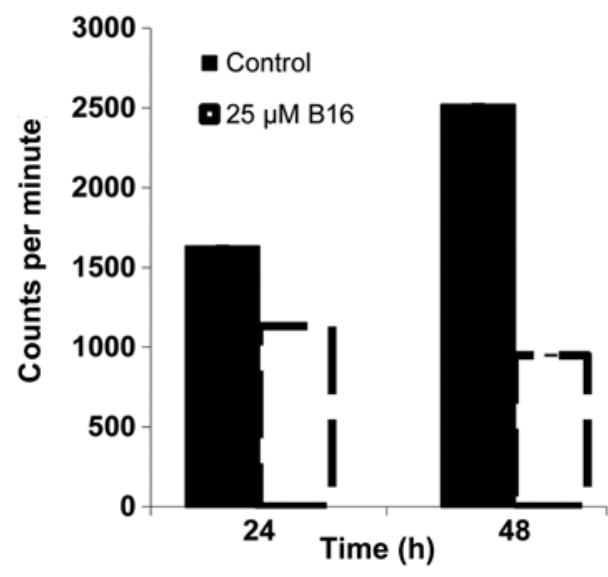

Figure 5. Inhibitory effect of B16 on [3 H]-dTTP incorporation of HeLa cells. HeLa cells were treated with $25 \mu \mathrm{M}$ B16. The amount of $\left[{ }^{3} \mathrm{H}\right]$-dTTP incorporation was analyzed by scintillation counting. Results are the mean \pm SD, $\mathrm{n}=3 .{ }^{*} \mathrm{P}<0.05$, significantly different from the control at the same level.

that it increased following treatment with B16 (Fig. 7A). This result suggests that B16 suppresses tumor growth. B16 treatment also reduced the expression of procaspase- 8 (Fig. 7B). As caspase- 8 is known to be involved in the Fas signaling apoptotic pathway, this result suggested that B16-induced apoptosis is mediated by the Fas signaling pathway. The expression level of the pro-apoptotic protein Bax was significantly upregulated by B16 treatment in a time-dependent manner, whereas the expression level of the anti-apoptotic protein Bcl-2 showed a tendency for downregulation compared to the control. Correspondingly, a marked increase in the $\mathrm{Bax} / \mathrm{Bcl}-2$ ratio was observed (Fig. 7C). The changes in expression of Bcl-2 family members further confirmed that the mitochondrial pathway is involved in B16-induced apoptosis. Moreover, the caspase cascade is associated with the intrinsic and extrinsic apoptotic pathways. Thus, taken together, these results suggested that B16 induced apoptosis in HeLa cells via a caspase- and mitochondrial-dependent pathway.

\section{Discussion}

Bispidinone (3,7-diazabicyclo[3.3.1]nonane) is present in the molecular structure of various alkaloids (e.g., diterpene, norditerpene and lupin); thus, this compound is of significant biological interest. To the best of our knowledge, there is no reported evidence for the use of bispidinone for cancer treatment, whereas its cytotoxicity has been documented. B16 is a novel bispidinone analog that can significantly suppress the proliferation of HeLa cells in a dose- and time-dependent manner. To the best of our knowledge, this is the first study on B16 induction of apoptosis in human cervical cancer cells and suggests a potential therapeutic role for B16 in the treatment of cervical cancer.

To examine the anticancer effects of B16 and ensure the accuracy of the results, we used several methods in this study to determine the effects of B16 on apoptosis. Cell cycle arrest and apoptosis can be induced by inhibitor-mediated blockage of DNA replication or DNA template damage due to radiation or other factors $(29,30)$. In this study, a DNA content assay determined that B16 inhibited HeLa cell proliferation via arrest of the cell division cycle during the $\mathrm{S}$ phase, in which cells replicate their DNA (31). Moreover, $\left[{ }^{3} \mathrm{H}\right]$-thymidine incorporation was inhibited by $\mathrm{B} 16$ treatment, indicating that the S-phase arrest was caused by inhibition of DNA replication. 
A

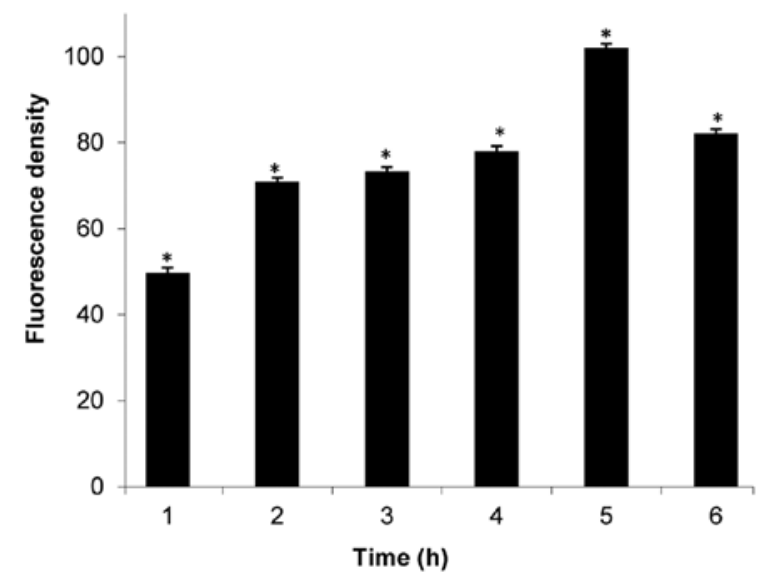

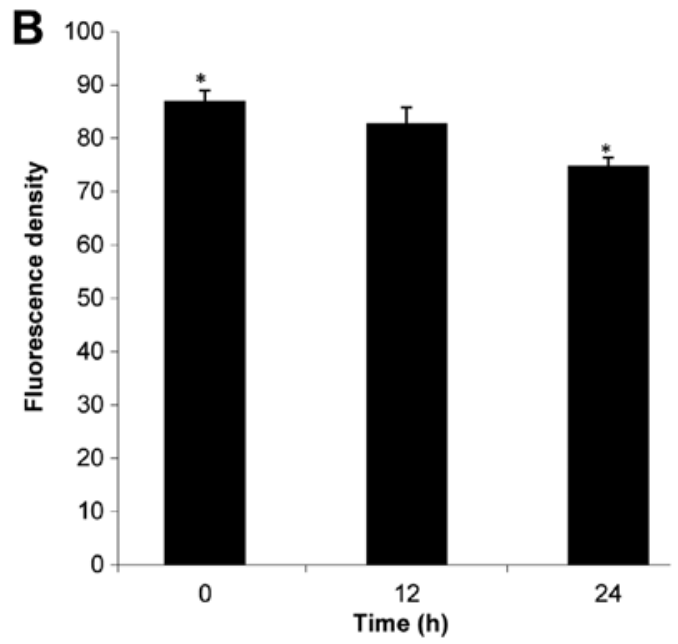

Figure. 6. Effects of B16 on ROS generation and mitochondrial-membrane potential $(\Delta \Psi \mathrm{m})$. (A) Cells treated with B16 were incubated with DCF-DA and the intracellular levels of ROS were determined by measuring the level of DCF fluorescence. (B) Cells were incubated with $25 \mu \mathrm{M}$ of B16 for varying lengths of time $(0-48 \mathrm{~h})$ and then analyzed by JC-1-derived fluorescence. Results are the mean $\pm \mathrm{SD}, \mathrm{n}=3$. * $\mathrm{P}<0.05$, significantly different from the control at the same level.

A

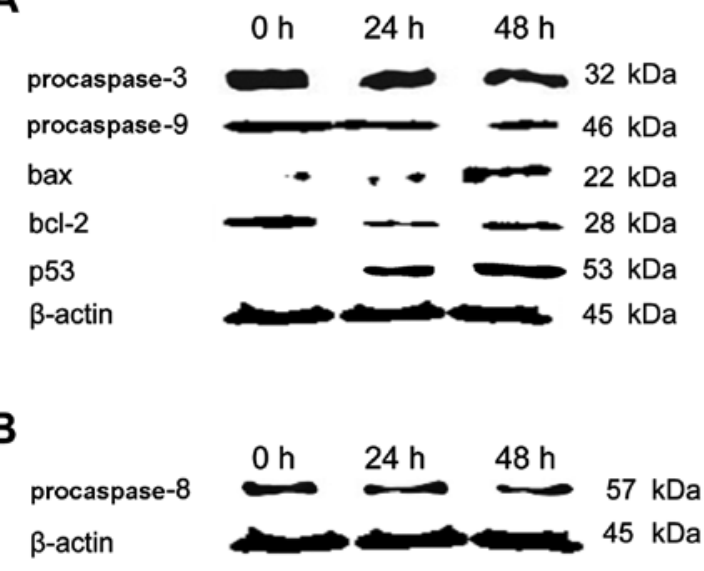

C

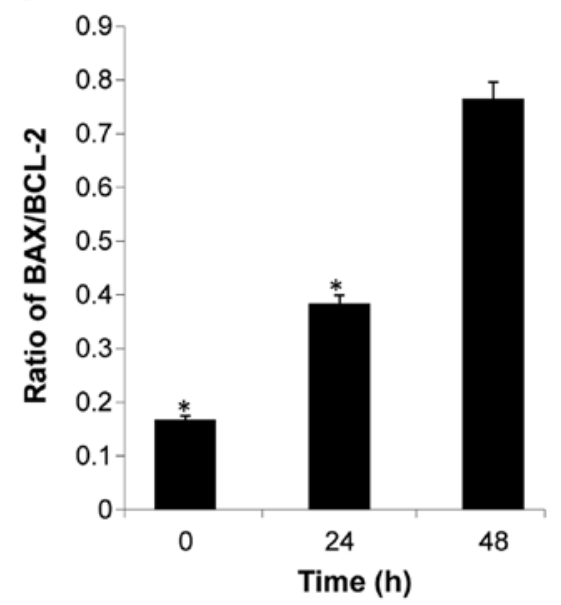

Figure 7. Involvement of protein activation in B16-induced apoptosis. HeLa cells were treated with $25 \mu \mathrm{M}$ B16 for 0,24 and 48 h. The expression of proteins was analyzed by western blotting. B16 regulates the expression of (A) Bax, Bcl-2, p53, procaspase-3 and procaspase-9 and decreases the expression of (B) procaspase- 8 as determined by western blotting. (C) Ratio of Bax/Bcl-2. Results are the mean $\pm S D, n=3$. ${ }^{*} \mathrm{P}<0.05$, significantly different from the control at the same level.

B16 also induced clear apoptosis-associated morphological changes, and the result of Annexin V-FITC/PI double staining indicated that B16 induced early apoptosis in HeLa cells.

The B16-induced HeLa cell apoptosis observed in the present study was associated with a significant increase in the levels of intracellular ROS and a disruption of MMP. The Bcl-2 family proteins Bax and Bcl-2 play important roles in the mitochondrial-mediated apoptotic pathway $(32,33)$. Bcl-2 prevents apoptosis by preserving mitochondrial integrity, and the ratio of Bax to Bcl-2 is crucial to sustaining drug-induced apoptosis via the mitochondrial-mediated apoptotic pathway (34). The present study has demonstrated that B16 upregulated the expression level of Bax and downregulated the expression level of Bcl-2, leading to an increase in the ratio of $\mathrm{Bax} / \mathrm{Bcl}-2$ protein levels. These findings add to the increasing evidence that $\mathrm{Bcl}-2$ family proteins play central roles in apoptosis.

In the intrinsic pathway of apoptosis, caspase activation is closely linked to the permeabilization of the outer mitochon- drial membrane. The release of mitochondrial cytochrome $c$ facilitates the formation of the apoptosome complex, consisting of Apaf-1 and caspase-9, which subsequently activates effector caspases such as caspase-3 and leads to apoptosis $(35,36)$. In the present study, caspase activation was determined by western blot assays using antibodies against activated procaspase-3, -8 , and -9 . The activation of caspase-3 and -9 was detected, indicating that B16 induced apoptosis via the intrinsic pathway. However, B16 also reduced the expression of caspase-8, which is an initiator caspase first activated through an external signal for cell death. Moreover, the level of p53, a well-known tumor-suppressor protein, was increased. Taken together, these results suggest that B16 induced apoptosis via the intrinsic and extrinsic pathways.

In conclusion, our results have demonstrated that B16 exerted an inhibitory effect on the growth of HeLa human cervical cancer cells, and that this effect was associated with the induction of S-phase arrest and the promotion of apoptosis. 
B16 induced apoptosis via an increase in ROS generation and depolarization of the mitochondrial membrane. Moreover, caspase cascades were activated following B16 treatment, confirming that the apoptosis induced by B16 was associated with the intrinsic and extrinsic pathways. The results of our study suggest that B16 suppresses cancer cell proliferation, induces cancer cell apoptosis, and inhibits cancer cell growth.

\section{Acknowledgements}

The authors would like to thank Dr Paramasivam Parthiban for providing bispidinone analogs. This study was partly supported by NRF-2011-0010160.

\section{References}

1. Bray F, Jemal A, Grey N, Ferlay J and Forman D: Global cancer transitions according to the Human Development Index (20082030): a population-based study. Lancet Oncol 13: 790-801, 2012.

2. Smith HO, Tiffany MF, Qualls CR and Key CR: The rising incidence of adenocarcinoma relative to squamous cell carcinoma of the uterine cervix in the United States - a 24-year populationbased study. Gynecol Oncol 78: 97-105, 2000.

3. Rein DT and Kurbacher CM: The role of chemotherapy in invasive cancer of the cervix uteri: current standards and future prospects. Anticancer Drugs 12: 787-795, 2001.

4. Gascoigne KE and Taylor SS: Cancer cells display profound intra-and interline variation following prolonged exposure to antimitotic drugs. Cancer Cell 14: 111-122, 2008.

5. Jemal A, Center MM, DeSantis C and Ward EM: Global patterns of cancer incidence and mortality rates and trends. Cancer Epidemiol Biomarkers Preg 19: 1893-1907, 2010.

6. Sherwood SW, Sheridan JP and Schimke RT: Induction of apoptosis by the anti-tubulin drug colcemid: relationship of mitotic checkpoint control to the induction of apoptosis in HeLa S3 cells. Exp Cell Res 215: 373-379, 1994.

7. Evan GI and Vousden KH: Proliferation, cell cycle and apoptosis in cancer. Nature 411: 342-348, 2001.

8. Pucci B, Kasten M and Giordano A: Cell cycle and apoptosis. Neoplasia 2: 291, 2000.

9. Xiao J, Huang G, Zhu C, Ren D and Zhang S: Morphological study on apoptosis HeLa cells induced by soyasaponins. Toxicol In Vitro 21: 820-826, 2007.

10. Dewson G and Kluck RM: Mechanisms by which Bak and Bax permeabilise mitochondria during apoptosis. J Cell Sci 122 2801-2808, 2009.

11. Zamzami N and Kroemer G: The mitochondrion in apoptosis: how Pandora's box opens. Nat Rev Mol Cell Biol 2: 67-71, 2001.

12. Simizu S, Takada M, Umezawa K and Imoto M: Requirement of caspase-3(-like) protease-mediated hydrogen peroxide production for apoptosis induced by various anticancer drugs. J Biol Chem 273: 26900-26907, 1998.

13. Liu MJ, Wang Z, Li HX, Wu RC, Liu YZ and Wu QY: Mitochondrial dysfunction as an early event in the process of apoptosis induced by woodfordin I in human leukemia K562 cells. Toxicol Appl Pharmacol 194: 141-155, 2004.

14. Kluck RM, Bossy-Wetzel E, Green DR and Newmeyer DD: The release of cytochrome $\mathrm{c}$ from mitochondria: a primary site for Bcl-2 regulation of apoptosis. Science 275: 1132-1136, 1997.

15. Putcha GV, Harris CA, Moulder KL, Easton RM, Thompson CB and Johnson EM: Intrinsic and extrinsic pathway signaling during neuronal apoptosis lessons from the analysis of mutant mice. J Cell Biol 157: 441-453, 2002.

16. Day TW, Huang S and Safa AR: c-FLIP knockdown induces ligand-independent DR5-, FADD-, caspase-8-, and caspase-9dependent apoptosis in breast cancer cells. Biochem Pharmacol 76: 1694-1704, 2008.

17. Graña X and Reddy EP: Cell cycle control in mammalian cells: role of cyclins, cyclin dependent kinases (CDKs), growth suppressor genes and cyclin-dependent kinase inhibitors (CKIs). Oncogene 11: 211-219, 1995.
18. Hall M and Peters G: Genetic alterations of cyclins, cyclindependent kinases, and Cdk inhibitors in human cancer. Adv Cancer Res 68: 67-108, 1996.

19. Dulić V, Kaufmann WK, Wilson SJ, Tisty TD, Lees E, Harper JW, Elledge SJ and Reed SI: p53-dependent inhibition of cyclin-dependent kinase activities in human fibroblasts during radiation-induced G1 arrest. Cell 76: 1013-1023, 1994.

20. MacLachlan TK, Sang N and Giordano A: Cyclins, cyclindependent kinases and cdk inhibitors: implications in cell cycle control and cancer. Crit Rev Eukaryot Gene 5: 127-156, 1995.

21. Murray A: Cell cycle checkpoints. Curr Opin Cell Biol 6: 872-876, 1994.

22. Parthiban P, Aridoss G, Rathika P, Ramkumar V and Kabilan S: Synthesis, stereochemistry and antimicrobial studies of novel oxime ethers of aza/diazabicycles. Bioorg Med Chem Lett 19: 6981-6985, 2009.

23. Haridas V, Rajgokul KS, Sadanandan S, Agrawal T, Sharvani V, Gopalakrishna M, Bijesh M, Kumawat KL, Basu A and Medigeshi GR: Bispidine-amino acid conjugates act as a novel scaffold for the design of antivirals that block Japanese encephalitis virus replication. PLoS Negl Trop Dis 7: 2005, 2013.

24. Tominaga $\mathrm{H}$, Ishiyama M, Ohseto $\mathrm{F}$, Sasamoto K, Hamamoto T, Suzuki K and Watanabe M: A water-soluble tetrazolium salt useful for colorimetric cell viability assay. Anal Commun 36: 47-50, 1999.

25. Lin SY, Liu JD, Chang HC, Yeh SD, Lin CH and Lee WS: Magnolol suppresses proliferation of cultured human colon and liver cancer cells by inhibiting DNA synthesis and activating apoptosis. J Cell Biochem 84: 532-544, 2002.

26. Bobyleva V, Pazienza TL, Maseroli R, Tomasi A, Salvioli S, Cossarizza A, Franceschi C and Skulachev VP: Decrease in mitochondrial energy coupling by thyroid hormones: a physiological effect rather than a pathological hyperthyroidism consequence. FEBS Lett 430: 409-413, 1998

27. Collins KL and Kelly TJ: Effects of T antigen and replication protein A on the initiation of DNA synthesis by DNA polymerase alpha-primase. Mol Cell Biol 11: 2108-2115, 1991.

28. Tang XQ, Feng JQ, Chen J, Chen PX, Zhi JL, Cui Y, Guo RX and Yu HM: Protection of oxidative preconditioning against apoptosis induced by $\mathrm{H} 2 \mathrm{O} 2$ in $\mathrm{PC} 12$ cells: mechanisms via MMP, ROS, and Bcl-2. Brain Res 1057: 57-64, 2005.

29. Shiff SJ, Qiao L, Tsai LL and Rigas B: Sulindac sulfide, an aspirin-like compound, inhibits proliferation, causes cell cycle quiescence, and induces apoptosis in HT-29 colon adenocarcinoma cells. J Clin Invest 96: 491-503, 1995.

30. Boehme SA and Lenardo MJ: Propriocidal apoptosis of mature $\mathrm{T}$ lymphocytes occurs at $\mathrm{S}$ phase of the cell cycle. Eur J Immunol 23: 1552-1560, 1993.

31. Zhang HS, Gavin M, Dahiya A, Postigo AA, Ma D, Luo RX, Harbour JW and Dean DC: Exit from G1 and S phase of the cell cycle is regulated by repressor complexes containing HDACRb-hSWI/SNF and Rb-hSWI/SNF. Cell 101: 79-89, 2000.

32. Thomas A, El Rouby S, Reed JC, Krajewski S, Silber R, Potmesil M and Newcomb EW: Drug-induced apoptosis in B-cell chronic lymphocytic leukemia: relationship between p53 gene mutation and bcl-2/bax proteins in drug resistance. Oncogene 12: 1055-1062, 1996

33. Yin X, Oltvai ZN and Korsmeyer SJ: BH1 and BH2 domains of Bcl-2 are required for inhibition of apoptosis and heterodimerization with Bax. Nature 369: 321-323, 1994.

34. Miyashita T, Krajewski S, Krajewska M, Wang HG, Lin H, Liebermann DA, Hoffman B and Reed JC: Tumor suppressor p53 is a regulator of bcl-2 and bax gene expression in vitro and in vivo. Oncogene 9: 1799-1805, 1994.

35. Fulda S and Debatin KM: Extrinsic versus intrinsic apoptosis pathways in anticancer chemotherapy. Oncogene 25: 4798-4811, 2006.

36. Saitoh M, Nagai K, Nakagawa K, Yamamura T, Yamamoto S and Nishizaki T: Adenosine induces apoptosis in the human gastric cancer cells via an intrinsic pathway relevant to activation of AMP-activated protein kinase. Biochem Pharmacol 67: 2005-2011, 2004. 